Article

\title{
Photonic Crystal Fiber Plasmonic Sensor Based on Dual Optofluidic Channel
}

\author{
Nan Chen ${ }^{1}$, Min Chang ${ }^{1}$, Xinglian Lu ${ }^{1}$, Jun Zhou ${ }^{1}$ and Xuedian Zhang ${ }^{1,2, *}$ \\ 1 School of Optoelectronic Information and Computer Engineering, University of Shanghai for Science and \\ Technology Shanghai Key Laboratory of Modern Optical System, 516 Jungong Rd, Shanghai 200093, China; \\ 181560053@st.usst.edu.cn (N.C.); changmin@usst.edu.cn (M.C.); 151360021@st.usst.edu.cn (X.L.); \\ 151360026@st.usst.edu.cn (J.Z.) \\ 2 Shanghai Key Laboratory of Molecular Imaging, Shanghai University of Medicine and Health Sciences, \\ Shanghai 201318, China \\ * Correspondence: xdzhang@usst.edu.cn
}

Received: 22 October 2019; Accepted: 23 November 2019; Published: 25 November 2019

\begin{abstract}
A hexagonal photonic crystal fiber (PCF) sensor with a dual optofluidic channel based on surface plasmon resonance (SPR) effect is proposed. The sensor characteristic is numerically explored by software integrated with the finite element method (FEM). The numerical results show that, when the analyte refractive index (RI) varies from 1.32 to 1.38 , high linearity between resonance wavelength and analyte RI is obtained and the value of adjusted $R^{2}$ is up to 0.9993 . Simultaneously, the proposed sensor has maximum wavelength sensitivity (WS) of $5500 \mathrm{~nm} / \mathrm{RIU}$ and maximum amplitude sensitivity (AS) of $150 \mathrm{RIU}^{-1}$, with an RI resolution of $1.82 \times 10^{-5}$ RIU. Besides, owing to a simple structure and good tolerance of the proposed sensor, it can be easily fabricated by means of existing technology. The proposed sensor suggests promising applications in oil detection, temperature measurement, water quality monitoring, bio-sensing, and food safety.
\end{abstract}

Keywords: photonic crystal fiber; surface plasmon resonance; fiber sensor; fabrication

\section{Introduction}

Surface plasmon polariton [1] (SPP) has attracted increasingly more attention recently. Generally, when light incidents to a metal-dielectric interface, the interaction between light and matter is produced at this interface with significant energy loss; as long as the phase matching condition (PMC) is satisfied, the plasmonic resonance coupling state can be maintained. The above phenomenon is known as "surface plasmon resonance" (SPR) [2,3]. In the last decades, SPR technology has been applied widely in various fields, such as food safety, liquid and gas detection, bio-sensing, drug detection, and so on [4-8]. Specially, by integrating the SPR effect, photonic crystal fiber (PCF) $[9,10]$ can play a more important role in sensors, owing to its small size and flexible structure. By varying PCFs' dimension and arrangement of the pores, it is possible to manipulate the sensitivity and resonance peak of the required PCF-SPR sensors.

Nowadays, increasingly more novel designs of PCF-SPR sensor are being designed and numerically analyzed. Some typical designs are as follows: Dash et al. proposed a biosensor based on PCF-SPR that showed refractive index (RI) sensitivity of $2000 \mathrm{~nm} / \mathrm{RIU}$ with a resolution of $5 \times 10^{-5} \mathrm{RIU}$ [11]. In 2014, Otupiri et al. proposed a novel birefringent PCF biosensor constructed on the SPR effect; for spectral interrogation (SI), the sensor resolution values yielded $5 \times 10^{-5}$ RIU for $\mathrm{HE}_{11}^{\mathrm{x}}$ modes and $6 \times 10^{-5} \mathrm{RIU}$ for $\mathrm{HE}_{11}^{\mathrm{y}}$ modes; for amplitude interrogation (AI), the sensor amplitude sensitivities (ASs) of $3 \times 10^{-5}$ RIU for $\mathrm{HE}_{11}^{\mathrm{x}}$ modes and $4 \times 10^{-5}$ RIU for $\mathrm{HE}_{11}^{\mathrm{y}}$ modes were obtained [12]. In 2015, selecting gold $(\mathrm{Au})$ and silver $(\mathrm{Ag})$ as the SPR activity metal, Fan et al. proposed two kinds of novel plasmonic 
RI sensors; their numerical results showed average sensitivities of $7040 \mathrm{~nm} / \mathrm{RIU}$ ( $\mathrm{Au}$ ) and $7017 \mathrm{~nm} / \mathrm{RIU}$ (Ag) with high linearity [13]. In 2016, Rifat et al. designed a novel PCF biosensor based on SPR phenomena, in which the sensing Au layer was wrapped outside the PCF; by using the wavelength interrogation (WI) mode, the designed sensor showed a maximum sensitivity of $14,000 \mathrm{~nm} / \mathrm{RIU}$ and a resolution of $1 \times 10^{-4}$ RIU [14]. In 2017, Wu et al. designed a side-polished D-shaped PCF-SPR sensor by a combination of experiment and simulation; the sensitivity was up to $21,700 \mathrm{~nm} / \mathrm{RIU}$ in the RI range of 1.33-1.34 [15]. Liu et al. proposed a PCF-SPR sensor with two open-ring channels; their sensor showed an average spectral sensitivity of $5500 \mathrm{~nm} / \mathrm{RIU}$ and a maximum resolution of $7.69 \times 10^{-6}$ RIU [16].

According to the above, most of the PCF-SPR sensors with excellent performance are mainly employed in RI detection, ranging from 1.32 to 1.38 for bio-sensing, and the PCF structure and processing techniques for designing these sensors vary. Therefore, we try to introduce the dual optofluidic channel in PCF and implement the proposed sensor with detection ranging from 1.32 to 1.38 , which can be applied in practical fields. In this paper, we propose and numerically analyze a PCF-SPR sensor with a simple structure. By investigating the transmission loss for different sizes of the innermost four pores, Au-filled central pore diameter of the PCF, and RI coefficients of the analytes, we find the structural parameters have significant effects on the resonance coupling between the polarized core mode and SPP mode. In particular, the RI of filling material will be helpful for improving the sensitivity of PCF-SPR sensors. The proposed sensor can be fabricated easily by employing the standard stack and draw PCF fabrication method.

\section{Numerical Modeling}

Figure 1 displays the schematic cross section of this PCF-SPR sensor. We propose a three-layer hexagonal lattice with an Au-filled central pore and the innermost enlarged four pores. Optofluidic channels are on both sides of the Au wire and analytes are introduced in the pore channels. An energy coupling effect can be generated by the SPP mode generated between Au in the central pore and the fundamental core mode of the filled analytes. In the proposed PCF, all pores are of a circular shape. The diameter of the PCF is $15 \mu \mathrm{m}$ and the pore-to-pore distance (pitch) is $\Lambda=2 \mu \mathrm{m}$. The diameter of pores of the two outer layers and analyte-filled pores is represented by $d_{1}$, the innermost enlarged pore diameter is represented by $d_{2}$, and diameter of the central Au-filled pore marked in orange is represented by $d_{A u}$. The RI detection range for the proposed sensor is from 1.32 to 1.38 and the RI of analyte marked in blue is represented by $n_{a}$. Fused silica is selected as the substrate material for PCF; its RI Sellmeier equation $[17,18]$ is described as follows:

$$
n^{2}(\lambda)=1+B_{1} \lambda^{2}\left(\lambda^{2}-C_{1}\right)^{-1}+B_{2} \lambda^{2}\left(\lambda^{2}-C_{2}\right)^{-1}+B_{3} \lambda^{2}\left(\lambda^{2}-C_{3}\right)^{-1}
$$

where $B_{1}=0.696163, B_{2}=0.4079426$, and $B_{3}=0.8974794 ; C_{1}=0.0046791 \mu \mathrm{m}^{2}, C_{2}=0.0135121 \mu \mathrm{m}^{2}$, and $C_{3}=97.93400 \mu \mathrm{m}^{2}$. The dielectric constant of $\mathrm{Au}$ filled in the central pore can be defined by the Drude-Lorentz (LD) model [19-24]:

$$
\varepsilon(\omega)=\varepsilon_{1}+i \varepsilon_{2}=\varepsilon_{\infty}-\frac{\omega_{p}^{2}}{\omega\left(\omega+i \omega_{c}\right)},
$$

where $\varepsilon_{\infty}$ is the dielectric constant of $A u$ at a high frequency and its value is 9.75 . The plasma frequency $\omega_{p}$ and the scattering frequency of electron $\omega_{c}$ are $1.36 \times 10^{16} \mathrm{~Hz}$ and $1.45 \times 10^{14} \mathrm{~Hz}$, respectively. 


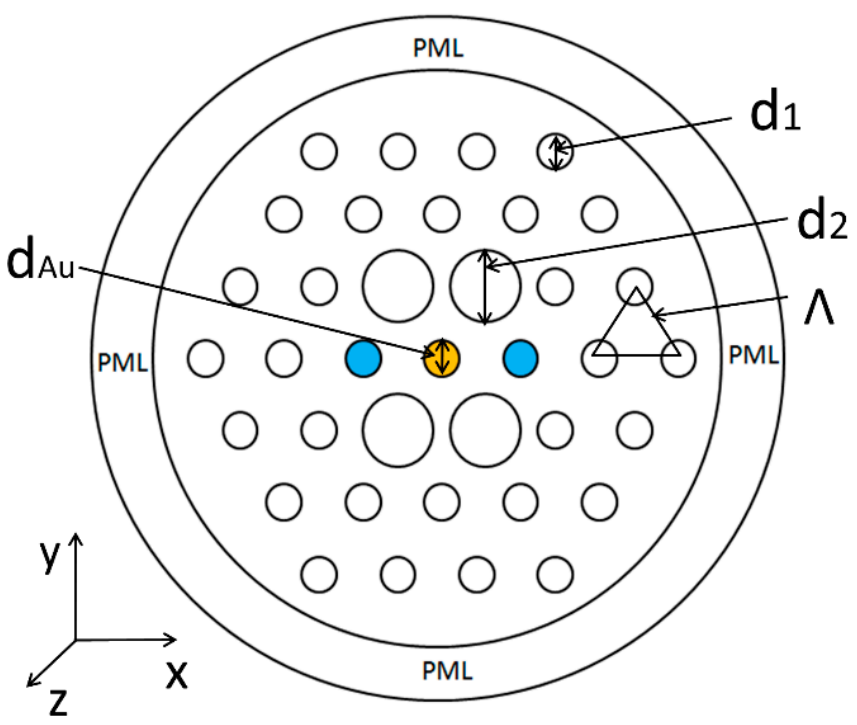

Figure 1. Cross-section diagram of the proposed photonic crystal fiber (PCF)-surface plasmon resonance (SPR) sensor.

The finite element method (FEM) $[25,26]$ is used to calculate the results with COMSOL5.2 software platform. When incident light propagates along the axial direction, different modes will distribute on the fiber end face, and modal analysis can be performed. Around the PCF structure, selecting the perfectly matched layer [27] (PML) as the boundary condition (BC) for absorbing scattered energy to improve accuracy of calculation and the transmission loss spectral can be characterized by confinement loss [28-30], which is expressed as follows:

$$
\alpha\left(\lambda, n_{a}\right)=8.686 \times \frac{2 \pi}{\lambda} \times \operatorname{Im}\left(n_{e f f}\right) \times 10^{3}(\mathrm{~dB} / \mathrm{mm}),
$$

where $\lambda$ and $\operatorname{Im}\left(n_{\text {eff }}\right)$ represent the operating wavelength in vacuum in $\mu \mathrm{m}$ and imaginary part of $n_{\text {eff }}$ for the fundamental mode (FM), respectively. When it comes to sensitivity, wavelength sensitivity (WS) and amplitude sensitivity (AS) are generally referred to. By means of the transmission loss, the proposed sensor performance parameters can be calculated. The WS and AS can be given by the following:

$$
S(\lambda)=\frac{\Delta \lambda_{\text {peak }}}{\Delta n_{a}}(n m / R I U)
$$

and

$$
S_{A}(\lambda)=\frac{1}{\alpha\left(\lambda, n_{a}\right)} \frac{\partial \alpha\left(\lambda, n_{a}\right)}{\partial n_{a}}\left(R I U^{-1}\right),
$$

respectively, where $\Delta \lambda_{\text {peak }}$ denotes the resonance wavelength changes and $\Delta n_{a}$ denotes variations in RI. Furthermore, the PML thickness is $2.5 \mu \mathrm{m}$; discretizing the whole cross section with fine triangular mesh elements of 130,897 . The source is an electromagnetic hybrid wave that is perpendicular to the $\mathrm{x}-\mathrm{y}$ plane, and the full-wave analysis method is utilized to investigate the mode distributions.

\section{Numerical Results and Discussions}

\subsection{Dispersion Relation}

The proposed PCF-SPR sensor operates on the basis of the interaction between evanescent field and central Au wire. The filling Au in the central pore between two analyte-filled cores can significantly enhance the birefringence and polarization-dependent loss for core FMs, resulting in visible differences of resonance peaks. As shown in Figure 2, the excited plasmonic modes are named as follows: (a) 0-SPP mode; (b) 1-SPP1 mode; (c) 1-SPP2 mode; (d) 2-SPP1 mode; (e) 2-SPP2 mode; (f) 3-SPP1 mode; and 
(g) 3-SPP2 mode [31]. The 1-SPP, 2-SPP, and 3-SPP modes usually have two degenerate states. In the universal band, the energy generated by resonance between FM and the 2-SPP mode is greater than that by resonance between FM and other SPP modes [32], so the 2-SPP mode is usually utilized to generate sensing signals. For the dual-core PCF-SPR sensor, the even mode and odd mode for $x$ - and $\mathrm{y}$-polarization (Figure $2 \mathrm{~h}-\mathrm{k}$ ) are excited simultaneously when incident light propagates along the $\mathrm{z}$ direction, and most of the energy is gathered in the dual-core. According to the calculated mode distributions, there are usually four states; they are the $x$-polarized even mode (x-EM) (Figure $2 h$ ); x-polarized odd mode (x-OM) (Figure 2i); y-polarized even mode (y-EM) (Figure 2j); and y-polarized odd mode (y-OM) (Figure 2k), respectively. Generally, the parity can be distinguished based on the direction of the arrow, while the even modes possess similar properties and both arrows point in the same direction, the odd modes have phase difference $\pi$ between two cores with two arrows in opposite directions [33,34]. Both even and odd polarized modes perform resonance coupling with 2-SPP modes being investigated. There are two cases of complete coupling resonance situations, as shown in Figure 3. The PMC of the sensor is satisfied and $\operatorname{Re}\left(_{\text {neff }}\right)$ and 2-SPP mode RI are equal at a resonant wavelength. In the process, the excited free electron oscillations owing to irradiation cause surface plasmon wave (SPW) in the metal-dielectric interface, so the evanescent field can be enhanced and the $\operatorname{Im}\left(n_{\text {eff }}\right)$ curve shows a sharp peak. There is only one distinct characteristic peak in the detected bands and the energy is close to 0 at the wavelengths of both sides away from the SPR peak, so it is very suitable for sensing applications. Additionally, it can be clearly seen that the sharpness of $\mathrm{y}$-OM is higher than that of $\mathrm{x}$-OM; in other words, the confinement loss of the former is stronger than that of the latter in this sensor. This can be explained in that the transmission loss is proportional to $\operatorname{Im}\left(n_{\text {eff }}\right)$.

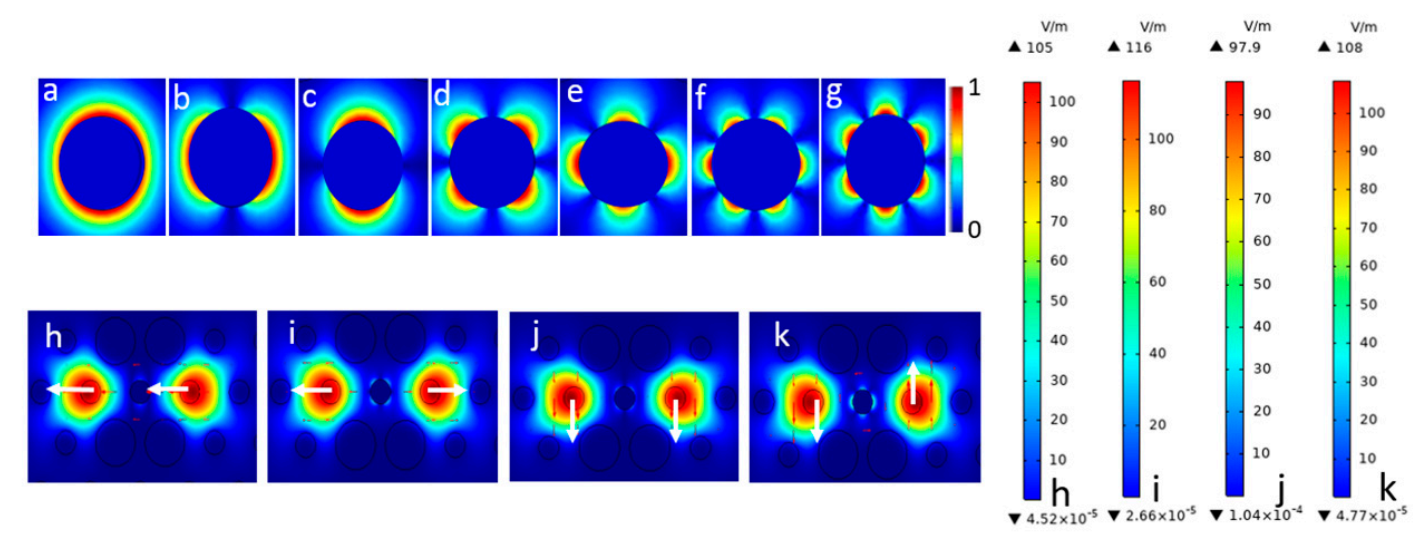

Figure 2. The electric field distributions. (a) 0-surface plasmon polariton (SPP) mode; (b) 1-SPP1 mode; (c) 1-SPP2 mode; (d) 2-SPP1 mode; (e) 2-SPP2 mode; (f) 3-SPP1 mode; and (g) 3-SPP2 mode. (h-k) The distributions of the even and odd supermodes (the arrows indicate the instantaneous electric field direction). 

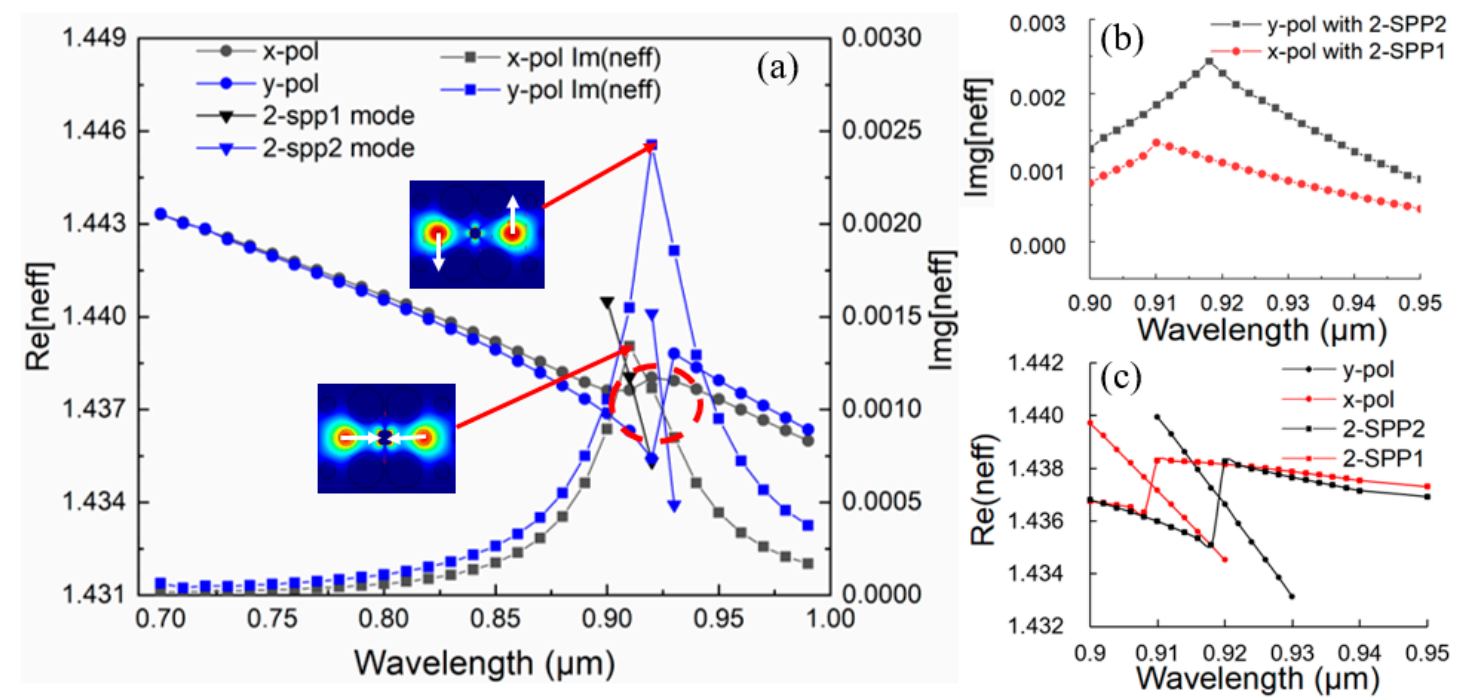

Figure 3. (a) The effective refractive index (RI) of the odd polarized core modes and SPP mode, and the imaginary part of RI for the proposed surface plasmon resonance (SPR) sensor with $\Lambda=2 \mu \mathrm{m}$, $d_{1}=0.8 \mu \mathrm{m}, d_{2}=1.4 \mu \mathrm{m}, d_{A u}=0.8 \mu \mathrm{m}$, and $n_{a}=1.35$; (b) $\operatorname{Im}\left[n_{e f f}\right]$ partial enlargement at wavelength ranging from 0.9 to 0.95 ; (c) $\operatorname{Re}\left[n_{e f f}\right]$ partial enlargement at wavelength ranging from 0.9 to 0.95 corresponding to the red dotted line.

\subsection{PCF-SPR Sensor Performance}

On the basis of the sensor's mode profile and satisfaction of PMCs, as shown in Figures 2 and 3, the calculated loss spectra changes owing to different structural parameters are shown in Figure 4. In Figure $4 \mathrm{a}, n_{a}$ is temporarily set as 1.35 , with structural parameters of $\Lambda=2 \mu \mathrm{m}, d_{1}=0.8 \mu \mathrm{m}$, and $d_{A u}$ $=0.8 \mu \mathrm{m}$, whereas the innermost enlarged pore diameter $d_{2}$ is taken as $1.4 \mu \mathrm{m}, 1.6 \mu \mathrm{m}$, and $1.8 \mu \mathrm{m}$, respectively. With the increment of $d_{2}$, the resonance peaks for $\mathrm{x}$ - and y-polarization produce a slight blue shift and confinement loss also decreases in this process. In addition, it can be clearly seen that the confinement loss reduction scale of the resonance peak for x-polarization is larger than that of $y$-polarization. Therefore, although both of the resonance peaks for x-polarization and y-polarization have decreased, the difference in energy between the two resonance peaks becomes more and more obvious. As a result, $d_{2}=1.8 \mu \mathrm{m}$ is adopted in order to distinguish the interference between the two confinement losses. In Figure $4 \mathrm{~b}$, making structural parameters $\Lambda=2 \mu \mathrm{m}, d_{1}=0.8 \mu \mathrm{m}$, and $d_{2}=1.8 \mu \mathrm{m}$, Au-filled central pore diameter $d_{A u}$ is taken as $0.6 \mu \mathrm{m}, 0.7 \mu \mathrm{m}$, and $0.8 \mu \mathrm{m}$, respectively. It can be intuitively found that the resonance wavelength moving is particularly sensitive to changes in $d_{A u}$. As $d_{A u}$ increases, the resonance peaks for $\mathrm{x}$ - and $\mathrm{y}$-polarization produce obvious red shifts and the confinement loss for y-polarization increases drastically; thus, the energy of the two polarized directions can also be clearly distinguished. On the basis of the above analysis, it is suitable to choose the structural parameters of $\Lambda=2 \mu \mathrm{m}, d_{1}=0.8 \mu \mathrm{m}, d_{2}=1.8 \mu \mathrm{m}$, and $d_{A u}=0.8 \mu \mathrm{m}$ to design the sensor.

In the following, $\mathrm{y}-\mathrm{OM}$ is employed to evaluate the performance of this sensor. The real part of the fundamental dual core mode RI is influenced strongly by the analyte RI, which determines the phase matching wavelength (PMW) between the core mode and the SPP mode. By varying the analyte RI from 1.32 to 1.38, a series of loss curves can be obtained, as shown in Figure 5a. The blue shift of resonance wavelengths of the y-polarized mode can be observed as $n_{a}$ increases. The reason is that the RI of the core mode increases and that of the SPP mode changes only slightly, which leads to a blue shift of the PMW. At the same time, the resonance peak shows an increasing trend. Figure $5 \mathrm{~b}$ shows the loss spectra of FM for different analyte RI with a single filled pore. Schematic diagram and mode field distributions are shown in the inset. Similarly, y-component FM is considered. The results in Figure $5 \mathrm{~b}$ cannot be compared with those in Figure 5a, because the loss spectra changes irregularly, the resonance peak increases firstly and then remains unchanged with the increase of $n_{a}$, and the 
operating wavelength range is more narrow. According to Figure 5, we investigated the relationship between analyte RI and resonance wavelength. Adopting Excel, linearly fitting discrete points were performed; the linear fitting curves are shown in Figure 6 and the obtained linear fitting formulas are shown as follows:

$$
\begin{aligned}
& \lambda_{1}=-0.975 n+0.3928(\mu \mathrm{m}),(1.32 \leq n \leq 1.38), \\
& \lambda_{2}=-0.825 n+0.1856(\mu \mathrm{m}),(1.32 \leq n \leq 1.38),
\end{aligned}
$$

where $n$ represents analyte RI in RIU. The quality of linearity can be judged by evaluating the adjusted $R^{2}$ (coefficient of determination) [35]. By calculation, the values of adjusted $R^{2}$ for $\lambda_{1}$ and $\lambda_{2}$ are 0.9993 and 0.9412 , respectively, which shows that the results of the former possess higher linearity compared with those of the latter.

In this sensor, a slight change in RI can cause significant spectra shifts. As shown in Figure 5a, the resonance wavelength changes regularly with the increase of analyte RI at intervals of 0.1 , which displays the wavelength dependence of the loss spectra owing to the change of analyte RI. The WS (also known as spectral sensitivity) is one of the important sensing performance parameters [36], as shown in Equation (4). Usually, $\Delta n_{a}$ is assumed to be 0.01 . In this sensor, the maximum $\Delta \lambda_{\text {peak }}$ is about $55 \mathrm{~nm}$ and the maximum spectral sensitivity is $5500 \mathrm{~nm} / \mathrm{RIU}$; combining all the cases, the average $\Delta \lambda_{\text {peak }}$ is about $10.2 \mathrm{~nm}$ and the average spectral sensitivity is $1020 \mathrm{~nm} / \mathrm{RIU}$. Usually, a wavelength resolution of $0.1 \mathrm{~nm}$ is assumed, and the RI resolution can reach $1.82 \times 10^{-5} \mathrm{RIU}$.
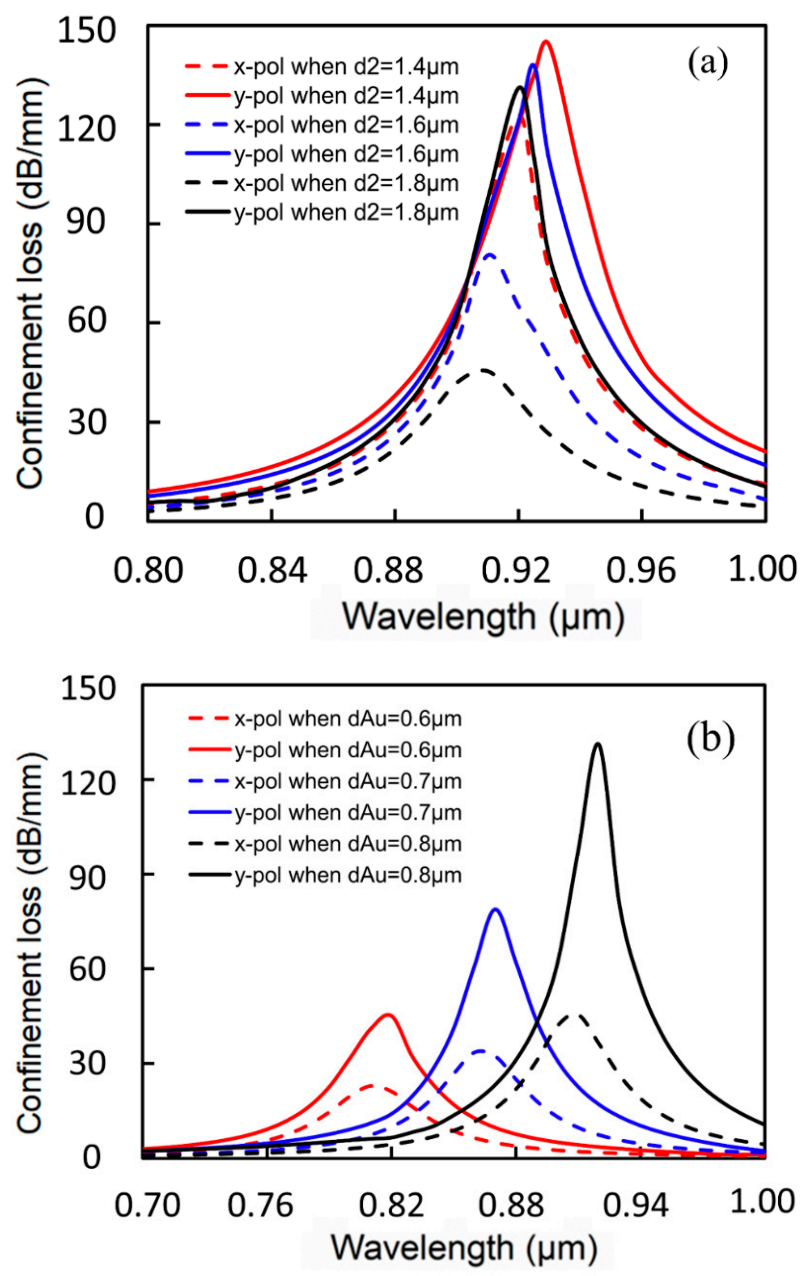

Figure 4. (a) Loss spectra of the fundamental mode (FM) for different sizes of the innermost enlarged pore $d_{2} ;(b)$ loss spectra of the plasmon peaks for different diameters of central Au-filled pore $d_{A u}$. 

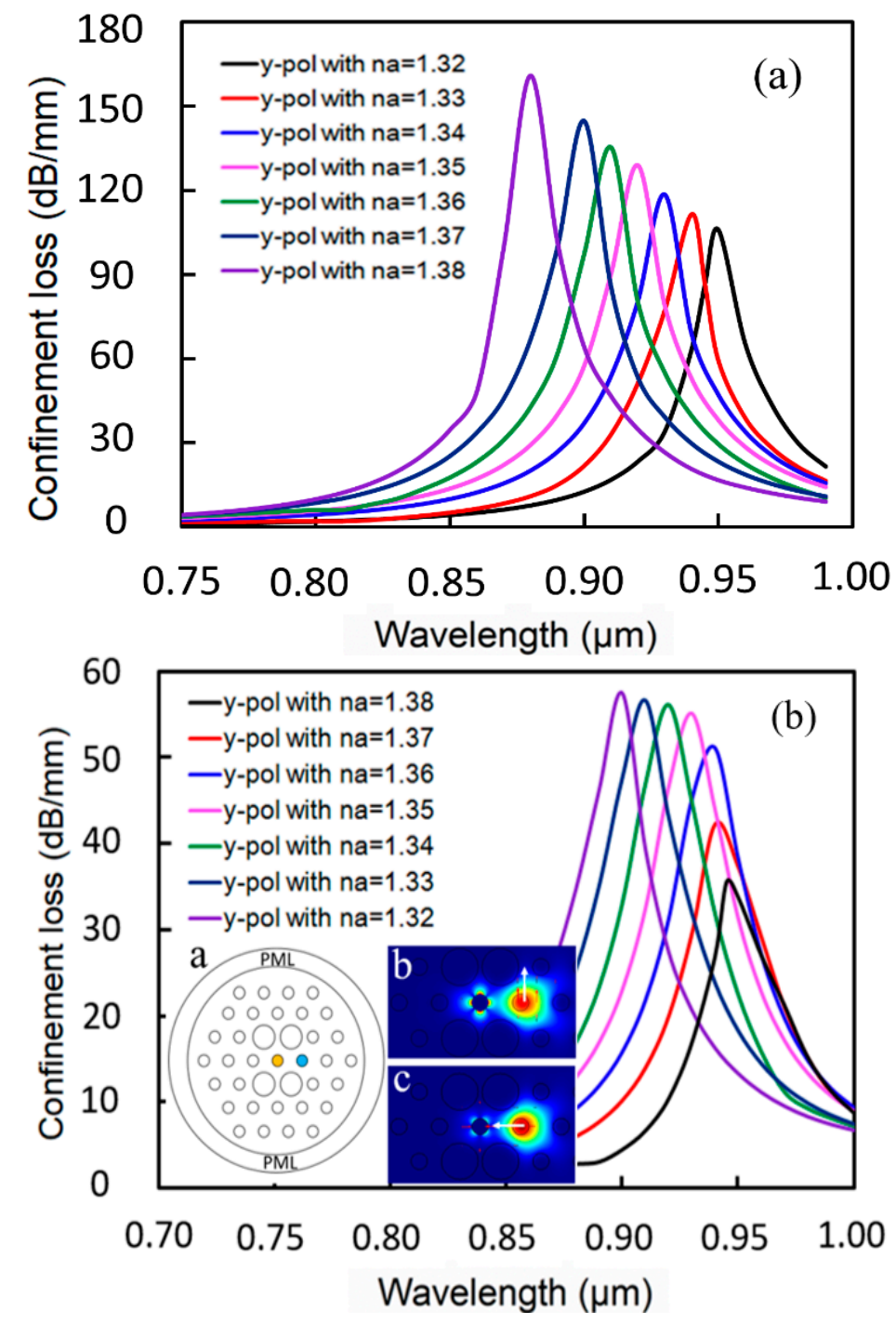

Figure 5. Loss spectra of FM in the proposed sensor structure for different analyte RI between 1.32 and 1.38 with (a) dual channel and (b) single channel.

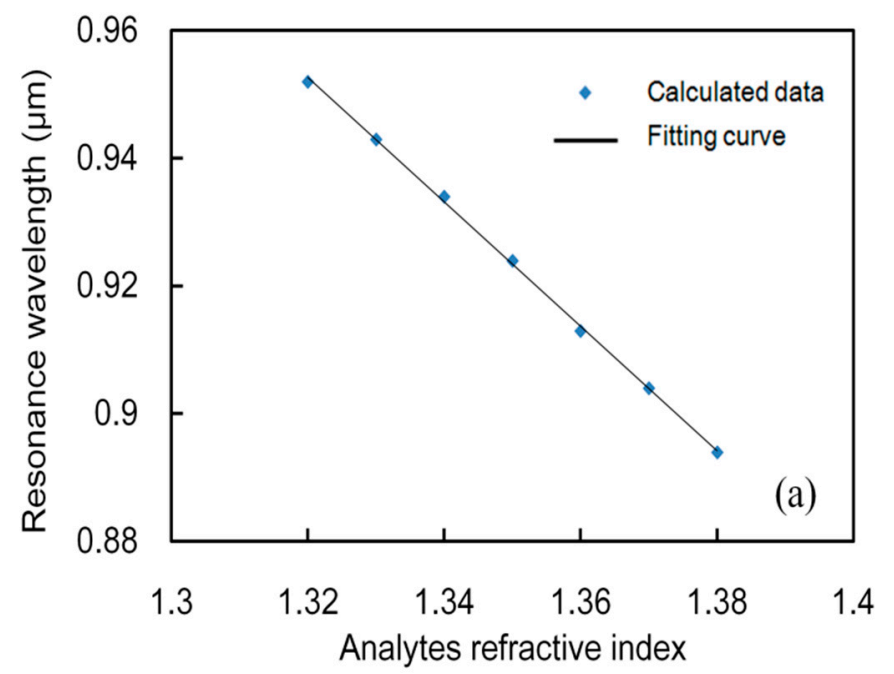

Figure 6. Cont. 


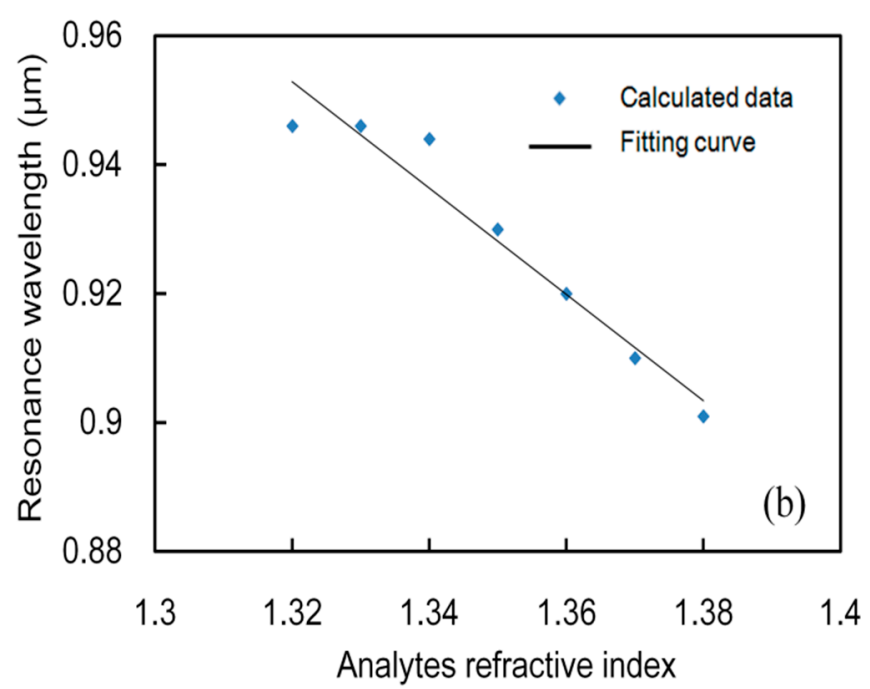

Figure 6. Linear fitting curve of the FM resonance wavelength versus analyte RI from 1.32 to 1.38 with (a) dual channel and (b) single channel.

Besides, the sensing AS is another important parameter [37], which can be calculated by Equation (5). The AS curves can be obtained by varying the analyte RI. Figure 7 shows that the AS increases gradually with the increase of analyte RI. Obviously, there is still better performance in the case of double pores filling. The maximum AS of this sensor is approximately $150 \mathrm{RIU}^{-1}$, when the analyte RI is 1.37. Therefore, this sensor has both high linearity and high sensitivity. Table 1 shows a comparison of our designed sensor with that of the existing typical designs. The magnitude of the maximum spectral sensitivity, the maximum amplitude sensitivity, the resolution, and the linearity for this proposed sensor can reach the performance level of the peers, which proves that our designed sensors possess good performance.

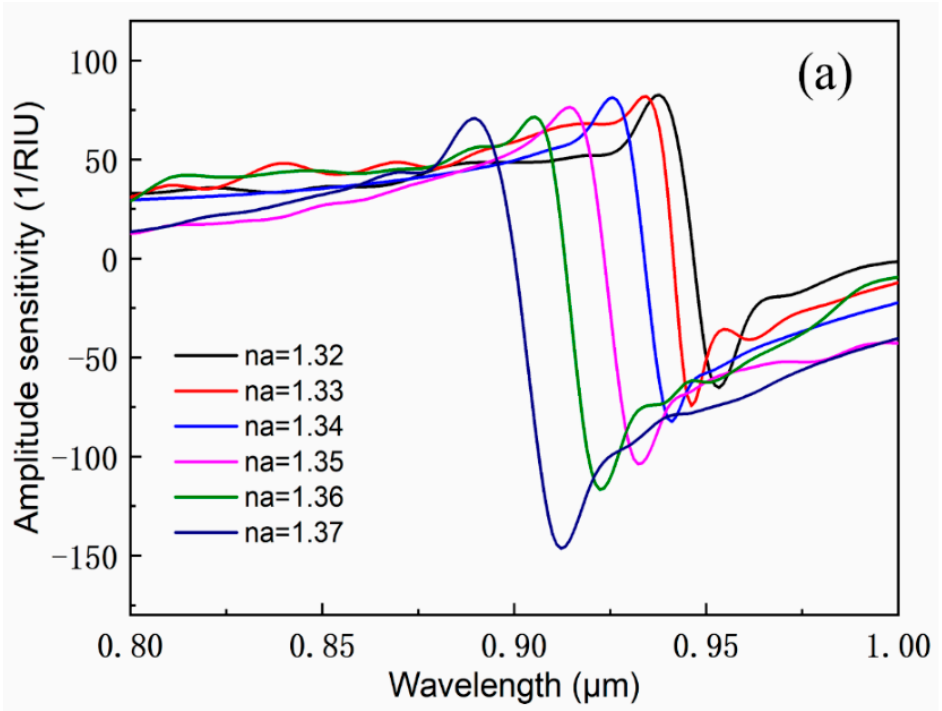

Figure 7. Cont. 


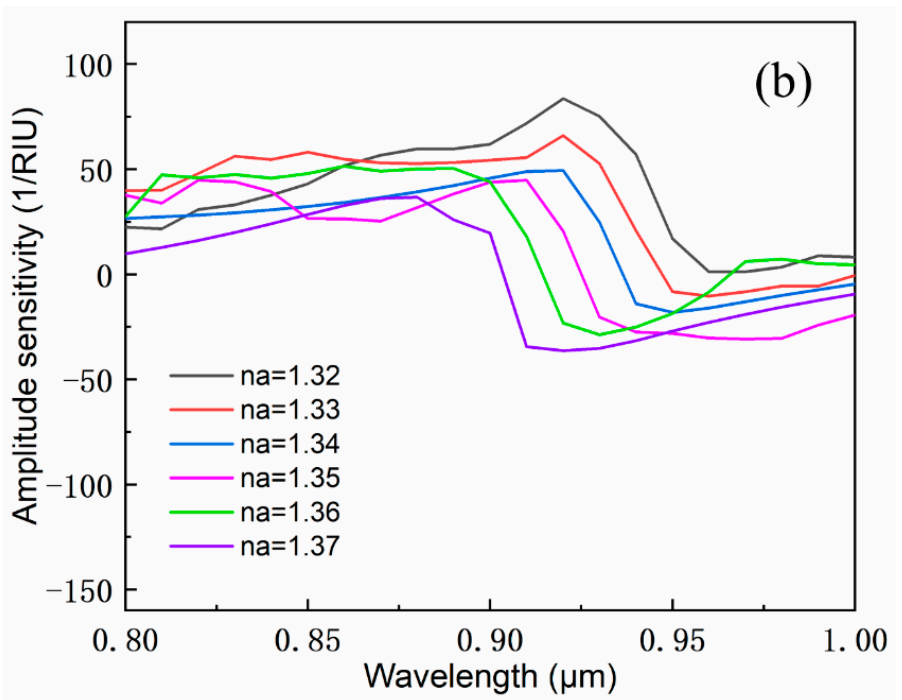

Figure 7. Amplitude sensitivity of the proposed sensor for different RI of the filled analytes with $\Lambda=2 \mu \mathrm{m}, d_{1}=0.8 \mu \mathrm{m}, d_{2}=1.8 \mu \mathrm{m}$, and $d_{A u}=0.8 \mu \mathrm{m}$ with (a) dual channel and (b) single channel.

Table 1. Performance comparison between the proposed sensor and prior typical sensors.

\begin{tabular}{|c|c|c|c|c|c|}
\hline Ref & Structure Type & $\begin{array}{l}\text { Max. Wav. Sens. } \\
\text { (nm/RIU) }\end{array}$ & $\begin{array}{l}\text { Max. Amp. Sens. } \\
\left(\text { RIU }^{-1}\right)\end{array}$ & Resolution (RIU) & Linearity \\
\hline [38] & $\begin{array}{l}\text { Long period } \\
\text { gratings }\end{array}$ & 1500 & N/A & $6.67 \times 10^{-5}$ & N/A \\
\hline [39] & $\begin{array}{l}\text { Planar waveguide } \\
\text { coupled resonators }\end{array}$ & 182 & N/A & $5.56 \times 10^{-4}$ & N/A \\
\hline [40] & $\begin{array}{l}\text { Capillary ring } \\
\text { resonators }\end{array}$ & 800 & N/A & $1.25 \times 10^{-4}$ & N/A \\
\hline [41] & Dual-polarized & 4600 & 420.4 & N/A & 0.9720 \\
\hline [5] & Outer coating & 4000 & 320 & $3.125 \times 10^{-5}$ & N/A \\
\hline [42] & Side polished & 5200 & $\mathrm{~N} / \mathrm{A}$ & $1.92 \times 10^{-5}$ & N/A \\
\hline This paper & $\begin{array}{l}\text { Dual optofluidic } \\
\text { channel }\end{array}$ & 5500 & 150 & $1.82 \times 10^{-5}$ & 0.9993 \\
\hline
\end{tabular}

\section{Fabrication Consideration}

Nowadays, the stack-and-draw method [43,44], extruded method, and gas producing method are common fabrication methods for PCF. Among them, the stack-and-draw method is relatively mature and varieties of the PCF structures can be drawn stably. Therefore, the stack-and-draw method is preferred for PCF fabrication. Firstly, the capillaries are usually stacked into a hexagonal structure, referred to in Figure 1, and the central capillaries are removed to form defects; these stacked capillaries are then placed in a thin-walled quartz tube of a suitable dimension, and a capillary is used to fill the peripheral voids to form a high-quality preform. Then, the preform is put into the fiber drawing tower, and the PCF with the desired dimensions can be drawn out. Secondly, Au wire is filled into the central pore of the PCF. All the pores except the central one are blocked with glue at one end of the PCF; Before filling Au wire, the appropriate internal pressure and precise heating temperature to soften glass are necessary for PCF, and then molten $\mathrm{Au}$ is pumped into the central pore, yielding the desired Au wire lengths. Eventually, after cleaving off the unfilled section, the desired PCF sensor is achieved [45]. Therefore, the PCF-SPR sensor we designed is simple in structure and can be completely fabricated using existing technology.

Finally, the design tolerance is considered. In the process of fiber fabrication, it is difficult to accurately control the size of the pores and pitch. The current technology can guarantee the error to 
be controlled at about $1 \%$ [46]. For the proposed sensor, $\pm 3 \%$ variation of $\Lambda$ and $d_{1}$ in the structure is investigated, as shown in Figure 8. Some slight changes in the loss and resonance wavelengths can be found. Especially, a change occurred in the case of $-3 \%$ of $\Lambda$. This could be explained in that the pore spacing decreases and the pores are denser as $\Lambda$ decreases, which shows a slightly more pronounced modulation for wavelength and energy. With the development of modern technology, precise control for $\Lambda$ and $d_{1}$ can be achieved, and these effects of the changes will be expected to be controlled.
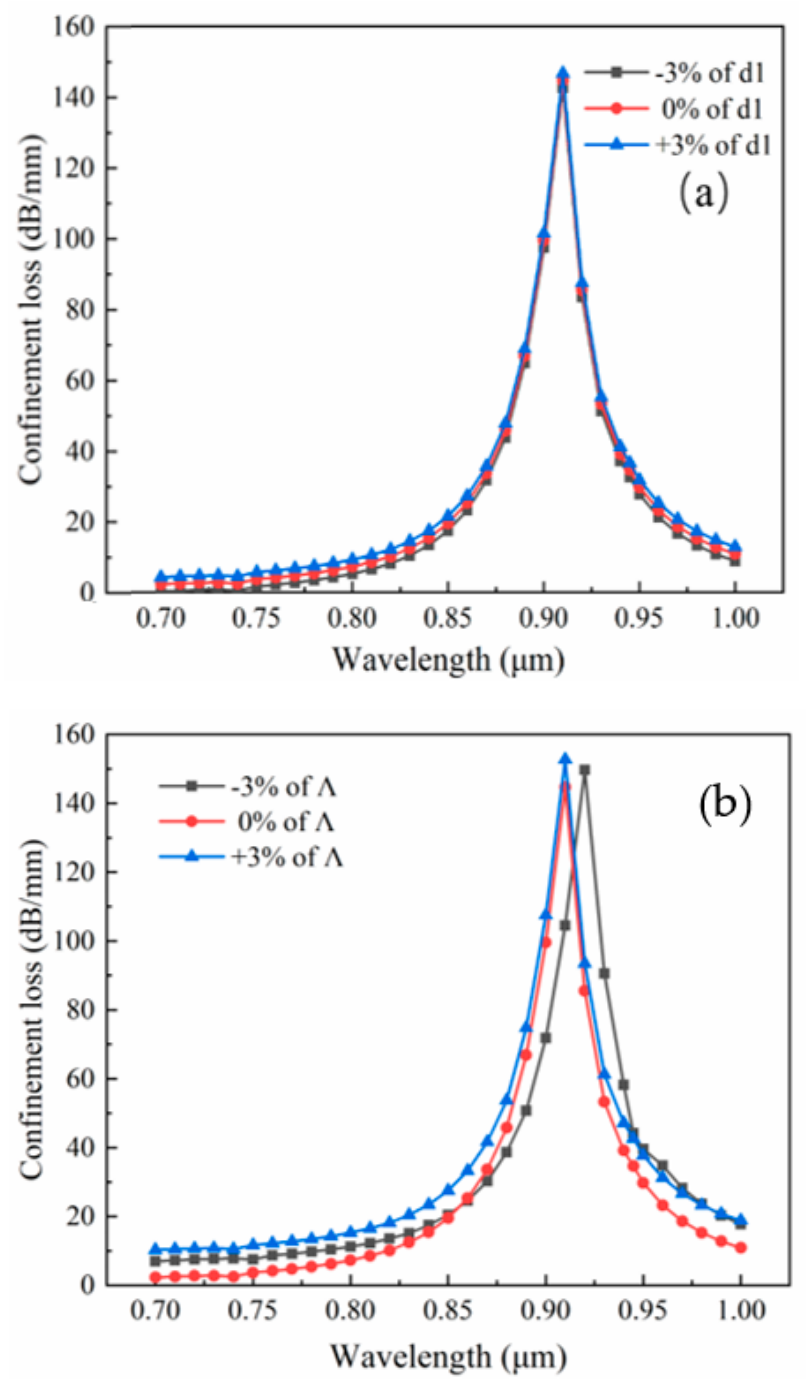

Figure 8. Loss spectra for variation of (a) $d_{1}$ of $\pm 3 \%$; (b) $\Lambda$ of $\pm 3 \%$ with $\Lambda=2 \mu \mathrm{m}, d_{1}=0.8 \mu \mathrm{m}$, $d_{2}=1.8 \mu \mathrm{m}, d_{A u}=0.8 \mu \mathrm{m}$, and $n_{a}=1.37$.

\section{Conclusions}

In conclusion, a practically simple, hexagonal PCF-SPR sensor with dual optofluidic channel is proposed and numerically investigated, which is characterized by Au-filled, innermost four enlarged pores and double pore-filled analytes. The FEM is employed to analyze the sensing characteristic by optimizing the structural parameters in PCF. After calculation, the results show that when $\Lambda=2 \mu \mathrm{m}$, $d_{1}=0.8 \mu \mathrm{m}, d_{2}=1.8 \mu \mathrm{m}$, and $d_{A u}=0.8 \mu \mathrm{m}$, the structure is suitable for sensing. According to the designs of Shuai et al. [47] and Qin et al. [48], they used multiple filling cores to detect RI larger than that of the fiber substrate and all achieved very good sensing performances. Although our paper investigates the RI range of 1.32-1.38, our sensors are also suitable for larger RI ranges. We believe that the proposed sensor will play a significant role in practical applications in the future. 
Author Contributions: The following statements should be used "conceptualization, N.C. and M.C.; methodology, N.C.; software, N.C.; validation, N.C., X.L. and M.C.; formal analysis, X.L.; investigation, J.Z.; resources, X.Z.; data curation, M.C.; writing-original draft preparation, N.C.; writing-review and editing, M.C.; visualization, J.Z. and N.C.; supervision, X.Z.; project administration, X.Z.; funding acquisition, X.Z."

Funding: This work was financially supported by University of Shanghai for Science and Technology (USST); National Key Scientific Apparatus Development of Special Item [project number: 2016YFF0101400].

Conflicts of Interest: The authors declare no conflict of interest.

\section{References}

1. Hu, D.J.J.; Ho, H.P. Recent advances in plasmonic photonic crystal fibers: design, fabrication and applications. Adv. Opt. Photonics 2017, 9, 257-314. [CrossRef]

2. Sun, B.; Chen, M.Y.; Zhou, J.; Zhang, Y.K. Surface Plasmon Induced Polarization Splitting Based on Dual-Core Photonic Crystal Fiber with Metal Wire. Plasmonics 2013, 8, 1253-1258. [CrossRef]

3. Liu, Q.; Li, S.; Li, H.; Zi, J.; Zhang, W.; Fan, Z.; An, G.; Bao, Y. Broadband Single-Polarization Photonic Crystal Fiber Based on Surface Plasmon Resonance for Polarization Filter. Plasmonics 2015, 10, 931-939. [CrossRef]

4. Popescu, V.A.; Puscas, N.N.; Perrone, G. Simulation of the Sensing Performance of a Plasmonic Biosensor Based on Birefringent Solid-Core Microstructured Optical Fiber. Plasmonics 2017, 12, 905-911. [CrossRef]

5. Rifat, A.A.; Mahdiraji, G.A.; Sua, Y.M.; Shee, Y.G.; Ahmed, R.; Chow, D.M.; Adikan, F.R.M. Surface Plasmon Resonance Photonic Crystal Fiber Biosensor: A Practical Sensing Approach. IEEE Photonics Technol. Lett. 2015, 27, 1628-1631. [CrossRef]

6. Otupiri, R.; Akowuah, E.K.; Haxha, S. Multi-channel SPR biosensor based on PCF for multi-analyte sensing applications. Opt. Express 2015, 23, 15716-15727. [CrossRef]

7. Yang, X.; Lu, Y.; Liu, B.; Yao, J. Analysis of Graphene-Based Photonic Crystal Fiber Sensor Using Birefringence and Surface Plasmon Resonance. Plasmonics 2017, 12, 489-496. [CrossRef]

8. Sazio, P.J.; Amezcuacorrea, A.; Finlayson, C.E.; Hayes, J.R.; Scheidemantel, T.J.; Baril, N.F.; Jackson, B.R.; Won, D.J.; Zhang, F.; Margine, E.R.; et al. Microstructured optical fibers as high-pressure microfluidic reactors. Science 2006, 311, 1583-1586. [CrossRef]

9. Russell, P. Photonic Crystal Fibers. J. Lightwave Technol. 2007, 24, 358-362.

10. Knight, J.C. Photonic crystal fibers and fiber lasers (Invited). J. Opt. Soc. Am. B-opt. Phys. 2007, 24, 1661-1668. [CrossRef]

11. Dash, J.N.; Jha, R. SPR Biosensor Based on Polymer PCF Coated With Conducting Metal Oxide. IEEE Photonics Technol. Lett. 2014, 26, 595-598. [CrossRef]

12. Otupiri, R.; Akowuah, E.K.; Haxha, S.; Ademgil, H.; AbdelMalek, F.; Aggoun, A. A Novel Birefrigent Photonic Crystal Fiber Surface Plasmon Resonance Biosensor. IEEE Photonics J. 2014, 6, 1-11. [CrossRef]

13. Fan, Z.; Li, S.; Liu, Q.; An, G.; Chen, H.; Li, J.; Chao, D.; Li, H.; Zi, J.; Tian, W. High Sensitivity of Refractive Index Sensor Based on Analyte-Filled Photonic Crystal Fiber With Surface Plasmon Resonance. IEEE Photonics J. 2015, 7, 1-9. [CrossRef]

14. Rifat, A.A.; Mahdiraji, G.A.; Shee, Y.G.; Shawon, M.J.; Adikan, F.R.M. A Novel Photonic Crystal Fiber Biosensor Using Surface Plasmon Resonance. Procedia Eng. 2016, 140, 1-7. [CrossRef]

15. Wu, T.; Shao, Y.; Wang, Y.; Cao, S.; Cao, W.; Zhang, F.; Liao, C.; He, J.; Huang, Y.; Hou, M.; et al. Surface plasmon resonance biosensor based on gold-coated side-polished hexagonal structure photonic crystal fiber. Opt. Express 2017, 25, 20313-20322. [CrossRef] [PubMed]

16. Liu, C.; Yang, L.; Lu, X.; Liu, Q.; Wang, F.; Lv, J.; Sun, T.; Mu, H.; Chu, P.K. Mid-infrared surface plasmon resonance sensor based on photonic crystal fibers. Opt. Express 2017, 25, 14227-14237. [CrossRef] [PubMed]

17. Cai, W.; Liu, E.; Feng, B. Dodecagonal photonic quasi-crystal fiber with high birefringence. J. Opt. Soc. Am. A Opt. Image Sci. Vision 2016, 33, 2108-2114. [CrossRef]

18. Hameed, M.F.; Heikal, A.M.; Younis, B.M.; Abdelrazzak, M.M.; Obayya, S.S. Ultra-high tunable liquid crystal-plasmonic photonic crystal fiber polarization filter. Opt. Express 2015, 23, 7007-7020. [CrossRef]

19. An, G.; Li, S.; Zhang, W.; Fan, Z.; Bao, Y. A polarization filter of gold-filled photonic crystal fiber with regular triangular and rectangular lattices. Opt. Commun. 2014, 331, 316-319. [CrossRef]

20. Liu, Q.; Li, S.; Li, J.; Dou, C.; Wang, X.; Wang, G.; Shi, M. Tunable Fiber Polarization Filter by Filling Different Index Liquids and Gold Wire Into Photonic Crystal Fiber. J. Lightwave Technol. 2016, 34, 2484-2490. [CrossRef] 
21. Zhao, Y.; Li, S.; Liu, Q.; Wang, X. Design of a novel photonic crystal fiber filter based on gold-coated and elliptical air holes. Opt. Mater. 2017, 73, 638-641. [CrossRef]

22. Heikal, A.M.; Hussain, F.F.K.; Hameed, M.F.O.; Obayya, S.S.A. Efficient Polarization Filter Design Based on Plasmonic Photonic Crystal Fiber. J. Lightwave Technol. 2015, 33, 2868-2875. [CrossRef]

23. Chen, H.; Li, S.; Ma, M.; Li, J.; Fan, Z.; Shi, M. Surface Plasmon Induced Polarization Filter Based on Au Wires and Liquid Crystal Infiltrated Photonic Crystal Fibers. Plasmonics 2016, 11, 459-464. [CrossRef]

24. Xue, J.; Li, S.; Xiao, Y.; Qin, W.; Xin, X.; Zhu, X. Polarization filter characters of the gold-coated and the liquid filled photonic crystal fiber based on surface plasmon resonance. Opt. Express 2013, 21, 13733-13740. [CrossRef] [PubMed]

25. Saitoh, K.; Koshiba, M. Numerical modeling of photonic crystal fibers. J. Lightwave Technol. 2005, 23, 3580-3590. [CrossRef]

26. Chen, H.; Li, S.; Ma, M.; Liu, Y.; Shi, M.; Liu, Q.; Cheng, T. Filtering Characteristics and Applications of Photonic Crystal Fibers Being Selectively Infiltrated With One Aluminum Rod. J. Lightwave Technol. 2016, 34, 4972-4980. [CrossRef]

27. Saitoh, K.; Koshiba, M.; Hasegawa, T.; Sasaoka, E. Chromatic dispersion control in photonic crystal fibers: application to ultra-flattened dispersion. Opt. Express 2003, 11, 843-852. [CrossRef]

28. Jocher, C.; Jauregui, C.; Voigtlander, C.; Stutzki, F.; Nolte, S.; Limpert, J.; Tünnermann, A. Fiber based polarization filter for radially and azimuthally polarized light. Opt. Express 2011, 19, 19582-19590. [CrossRef]

29. An, G.; Li, S.; Yan, X.; Yuan, Z.; Zhang, X. High-birefringence photonic crystal fiber polarization filter based on surface plasmon resonance. Appl. Opt. 2016, 55, 1262-1266. [CrossRef]

30. Yang, X.; Lu, Y.; Liu, B.; Yao, J. Polarization Characteristics of High-Birefringence Photonic Crystal Fiber Selectively Coated with Silver Layers. Plasmonics 2018, 13, 1035-1042. [CrossRef]

31. Nagasaki, A.; Saitoh, K.; Koshiba, M. Polarization characteristics of photonic crystal fibers selectively filled with metal wires into cladding air holes. Opt. Express 2011, 19, 3799-3808. [CrossRef] [PubMed]

32. Schmidt, M.A.; Russell, P.S. Long-range spiralling surface plasmon modes on metallic nanowires. Opt. Express 2008, 16, 13617-13623. [CrossRef] [PubMed]

33. Li, P.; Zhao, J. Polarization-dependent coupling in gold-filled dual-core photonic crystal fibers. Opt. Express 2013, 21, 5232-5238. [CrossRef] [PubMed]

34. Wang, J.; Pei, L.; Weng, S.; Wu, L.; Huang, L.; Ning, T.; Li, J. Magneto-Modulating Polarization Converter Based on a Dual-Core Photonic Crystal Fiber. J. Lightwave Technol. 2017, 35, 2772-2777. [CrossRef]

35. Shuai, B.; Xia, L.; Zhang, Y.; Liu, D. A multi-core holey fiber based plasmonic sensor with large detection range and high linearity. Opt. Express 2012, 20, 5974-5986. [CrossRef]

36. Wang, F.; Sun, Z.; Liu, C.; Sun, T.; Chu, P.K. A Highly Sensitive Dual-Core Photonic Crystal Fiber Based on a Surface Plasmon Resonance Biosensor with Silver-Graphene Layer. Plasmonics 2017, 12, 1847-1853. [CrossRef]

37. Liu, C.; Su, W.; Liu, Q.; Lu, X.; Wang, F.; Sun, T.; Chu, P.K. Symmetrical dual D-shape photonic crystal fibers for surface plasmon resonance sensing. Opt. Express 2018, 26, 9039-9049. [CrossRef]

38. Rindorf, L.H.; Bang, O. Highly sensitive refractometer with a photonic-crystal-fiber long-period grating. Opt. Lett. 2008, 33, 563-565. [CrossRef]

39. Hu, J.; Carlie, N.; Feng, N.; Petit, L.; Agarwal, A.; Richardson, K.; Kimerling, L. Planar waveguide-coupled, high-index-contrast, high-Q resonators in chalcogenide glass for sensing. Opt. Lett. 2008, 33, 2500-2502. [CrossRef]

40. Sumetsky, M.; Windeler, R.S.; Dulashko, Y.; Fan, X. Optical liquid ring resonator sensor. Opt. Express 2007, 15, 14376-14381. [CrossRef]

41. Hasan, M.R.; Akter, S.; Rifat, A.A.; Rana, S.; Ahmed, K.; Ahmed, R.; Subbaraman, H.; Abbott, D. Spiral Photonic Crystal Fiber-Based Dual-Polarized Surface Plasmon Resonance Biosensor. IEEE Sens. J. 2018, 18, 133-140. [CrossRef]

42. Dash, J.N.; Jha, R. Highly sensitive D shaped PCF sensor based on SPR for near IR. Opt. Quantum Electron. 2016, 48, 137. [CrossRef]

43. Saghaei, H.; Heidari, V.; Ebnali-Heidari, M.; Yazdani, M.R. A systematic study of linear and nonlinear properties of photonic crystal fibers. Optik 2016, 127, 11938-11947. [CrossRef] 
44. Chen, N.; Zhang, X.; Nie, F.; Lu, X.; Chang, M. Dispersion-compensating photonic crystal fiber with wavelength tunability based on a modified dual concentric core structure. J. Mod. Opt. 2018, 65, 1459-1465. [CrossRef]

45. Lee, H.W.; Schmidt, M.A.; Tyagi, H.K.; Sempere, L.P.; Russell, P.S.J. Polarization-dependent coupling to plasmon modes on submicron gold wire in photonic crystal fiber. Appl. Phys. Lett. 2008, 93, 111102. [CrossRef]

46. Jiang, L.-H.; Yi, Z.; Hou, L.-T.; Peng, J. Design of highly birefringent SF57 soft glass PCF with low effective mode area. J. Infrared Millimeter Waves 2014, 33, 222-226.

47. Shuai, B.; Xia, L.; Liu, D. Coexistence of positive and negative refractive index sensitivity in the liquid-core photonic crystal fiber based plasmonic sensor. Opt. Express 2012, 20, 25858-25866. [CrossRef]

48. Qin, W.; Li, S.; Yao, Y.; Xin, X.; Xue, J. Analyte-filled core self-calibration microstructured optical fiber based plasmonic sensor for detecting high refractive index aqueous analyte. Opt. Lasers Eng. 2014, 58, 1-8. [CrossRef]

(C) 2019 by the authors. Licensee MDPI, Basel, Switzerland. This article is an open access article distributed under the terms and conditions of the Creative Commons Attribution (CC BY) license (http://creativecommons.org/licenses/by/4.0/). 